\title{
Municipal solid waste selective collection and tourism
}

\author{
E. C. Rada ${ }^{1}$, C. Zatelli ${ }^{2}$ \& P. Mattolin ${ }^{2}$ \\ ${ }^{I}$ Department of Civil, Environmental and Mechanical Engineering, \\ University of Trento, Italy \\ ${ }^{2}$ Agency for the Effluent Treatments, Italy
}

\begin{abstract}
This paper concerns the interaction between tourism and the selective collection of municipal solid waste (MSW). Data for an Italian province are shown, zooming in on five municipalities characterised by the high presence of tourists along the year. Information on the selective collection organisation is presented (also based on the presence of eco-centers). The highest tourist months are in winter and summer and their effect is seen in the increase of the factions connected with the tourists meals and also the increase of residual MSW. The monthly peaks of waste generation are very high, but the final results in terms of selective collection efficiency seem to not be affected (being even higher than $80 \%$, a value that is better than the one obtained at provincial scale). Also the presence of decentralised landfills did not discourage the source separation that changed significantly in about a decade. Moreover, the trend of tourists towards shorter periods of holiday does not affect selective collection; possibly because they are used to coming back to the same municipality, where they have already learned the local principles of source separation.
\end{abstract}

Keywords: municipal solid waste, selective collection, SRF, tourism, tourist.

\section{Introduction}

Municipal Solid Waste (MSW) management has become one of the most discussed and analysed topics during the years. The planning of a good MSW management depends not only on the waste legislation at national and international level but also on the economic and tourist aspects of each country, region or city. Recently it was introduced the likelihood to design a MSW 
management that can and must be energy-efficient, environmentally friendly and economically sustainable [1-4]. The authority in charge must plan the MSW management taking into account the waste hierarchy: prevention, preparation for reuse, recycling, energy recovery and disposal as indicated in the EU legislation: 75/439/CEE, 91/689/CEE and 2006/12/CE.

Today, when a MSW management plan is proposed, also the citizens help to its improvement thanks to their implications as active part of the entire system [5-8]. Their opinions and suggestions are very helpful for the achievement of a good and economically sustainable MSW management.

During the years, it was demonstrated that the MSW management is more difficult to plan in areas where tourism has an important influence [9-11]. Firstly, the attention was put on the MSW management in islands [12, 13] and only nowadays also tourist areas in specific regions were considered.

The present paper wishes to contribute to MSW management and planning in the tourist areas. The authors propose an overview of the last 30 years of MSW management in the North of Italy, in a region where the tourist fluxes are significant thanks to the attractive characteristics of the area (lakes and mountains).

\section{Materials and methods}

In Italy the first decree that deals with quantitative problems of MSW selective collection (SC) was the Ronchi Decree in 1997. In the chosen case-study in 1997 the province analysed in this paper issued on January $26^{\text {th }}$ the D.P.G.P. legislation (TULP) regarding the environmental protection from pollution, as imposed from [14]. Article 63 of this regulation, imposes besides recycling and composting also the implementation of $\mathrm{SC}$ in order to favour indirectly the energy recovery from MSW.

The first step in order to improve the MSW management in the chosen province was made through the regulation L.P. 29/82 that forbad the open dump (300 cases were found in that province in 1982) and imposed sanitary landfills ( 7 controlled landfill were built in the following years). In 1993 the first disposal plan for MSW was developed, followed by updates: 1997, 2002 and 2006. In the following years a continuous update of data on waste was performed. However, a significant change in the MSW management was introduced in Germany through the Topfer Decree in 1991. As a consequence, in the Italian province, in the second MSW plan (1997), the material recovery facilities (MRF) were proposed. In the year 1998, the same province issued the L.P. 5/1998 regulation in order to give information about the organization and the development of SC, and to minimize the residual MSW (RMSW) landfilling.

The first recycling consortium was established in 1994 and named CONAI (national consortium of packaging) for the collection, recycling and recovery of paper, cardboard, glass, plastics and metals. In the following years the number of consortiums increased considerably and each of them specialized itself in one type of waste. The food waste selective collection was introduced in the middle of the 1990s. 
The chosen province, today, has 16 valley communities (Figure 1), from which 6 are very tourist (the inhabitants increase in 2012 varied from $65 \%$ to $113 \%$ in the two most tourist ones, and from $22 \%$ to $40 \%$ in the other four). Concerning the remaining communities, in the same year, in five of them the inhabitants increase was between $9.5 \%$ and $13 \%$, instead in the other 5 , a very low tourist ratio was reported $(1.2 \%-4 \%)[15]$.

\section{Valley communities in the Province of Trento}

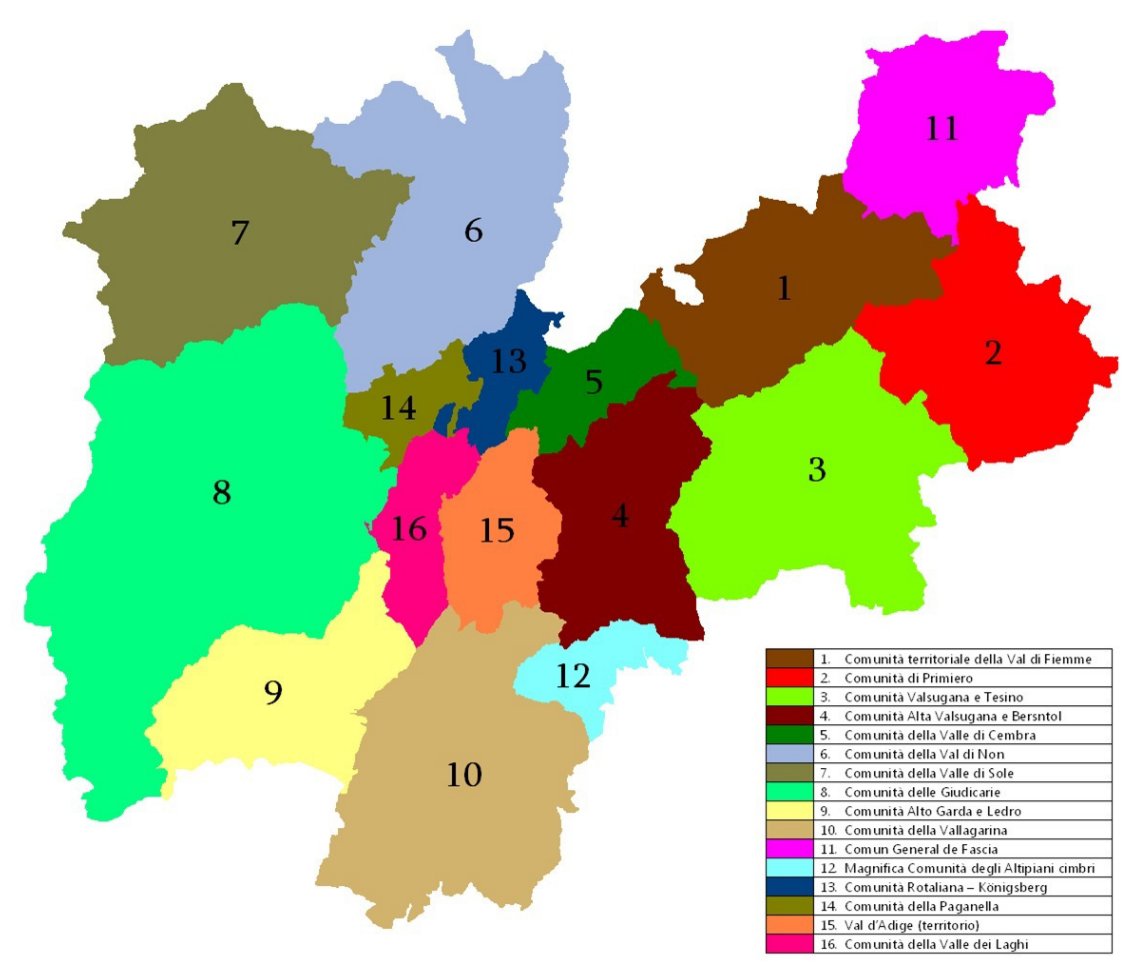

Figure 1: The valley communities in the analysed province.

SC in the province was performed since the 90's with three main streams: recyclable materials, food waste and residual materials. Today the SC is performed with different systems: home collection (kerbside), street collection and eco-stations, for specific fractions or mixed fractions $[16,17]$. The increase of SC efficiency has a strong effect on waste-to-energy options [18, 19]. In 2012, 132 fixed eco-centers and 2 mobile (CRM - center for material collection) and 14 zonal eco-centers (CRZ) operated in the chosen province. The maximum 
and minimum percentage of SC in all territories and also the per-capita waste production for the years 2000 and 2012 are reported in Table 1. In Figure 2 the evolution of $\mathrm{SC}$, at provincial level, for the chosen case study is reported.

Table 1: Percentage of SC, per-capita RMSW and total waste production.

\begin{tabular}{|c|c|c|c|c|c|c|c|c|}
\hline Year & \multicolumn{2}{|c|}{$\%$ SC } & \multicolumn{2}{c|}{$\begin{array}{c}\text { SC } \\
\text { (kg/inh. eq. })\end{array}$} & \multicolumn{2}{c|}{$\begin{array}{c}\text { RMSW } \\
\text { (kg/inh. eq. }\end{array}$} & \multicolumn{2}{c|}{$\begin{array}{c}\text { Total } \\
\text { (kg/inh. eq. })\end{array}$} \\
\hline & $\min$ & Max & $\min$ & $\max$ & $\min$ & $\max$ & $\min$ & $\max$ \\
\hline 2000 & 10 & 19 & 41 & 95 & 376 & 525 & 446 & 612 \\
\hline 2012 & 56 & 86 & 202 & 340 & 56 & 193 & 363 & 496 \\
\hline
\end{tabular}

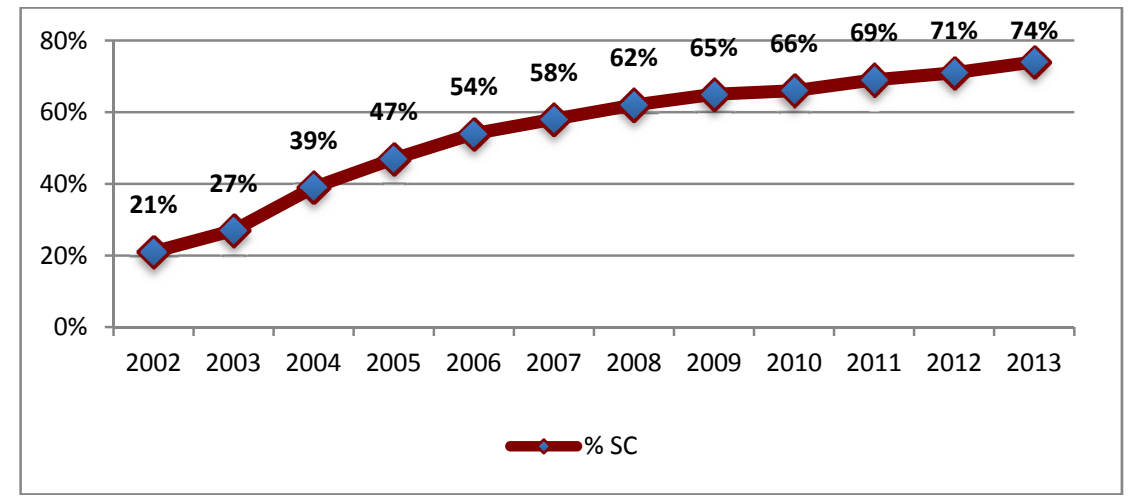

Figure 2: $\mathrm{SC}$ dynamics in the last decade in the chosen province.

The SC efficiency in the chosen province has been incentivised thanks to the national and local legislation, in particular D. Lgs. 36/2003, 296/2006 and $152 / 2006$, that forbad since 2007 the landfilling of materials that can be valorised energetically or have a LHV higher than $13 \mathrm{MJ} / \mathrm{kg}$. The regulation also asked a $65 \%$ of SC efficiency before the end of 2012.

For the development of the research five case-studies were analysed taking into account the tourist influence:

$>$ Case 1: Val di Fassa, that has 7 very tourist municipalities located between 1200 and $1500 \mathrm{~m}$ s.l.m., with about $318 \mathrm{~km}^{2}$ and an increase of population of about $112 \%$, due to tourist fluxes;

$>$ Case 2: Val di Sole, that has 14 tourist municipalities located at $650 \mathrm{~m}$ s.l.m., with about $610 \mathrm{~km}^{2}$ and an increase of population of about $65 \%$;

$>$ Case 3: Val di Fiemme, that has 11 tourist municipalities located between 900 and $1200 \mathrm{~m}$ s.l.m., with about $415 \mathrm{~km}^{2}$ and an increase of population of about $39 \%$; 
$>$ Case 4: Giudicarie, that has 40 tourist municipalities located between 270 and $3558 \mathrm{~m}$ s.l.m., with about $1,176 \mathrm{~km}^{2}$ and an increase of population of about $31 \%$;

Case 5: Val di Non, that has 38 municipalities located between $270 \mathrm{~m}$ and $2678 \mathrm{~m}$ s.l.m., with about $635 \mathrm{~km}^{2}$ and an increase of population of about $10 \%$.

With reference to the selected areas, the MSW management was analysed taking into account the production, collection and treatment/disposal.

\section{Results}

In Figure 3 the dynamics of the rate between inhabitants equivalent and inhabitants resident from 2002 to 2012 is reported for the proposed case studies and for the entire province. It can be noticed that for the cases with high number of municipalities but not all tourist (Val di Non and Giudicarie), the rate has a decrease of about $-2 \%$ and $-18 \%$ respectively. In the other three cases, the most tourist ones, the rate had an increase between $14 \%$ and $21 \%$, demonstrating that the tourists come back every year in the same area. However, the resident inhabitants increase in the last decade in the case studies from $4 \%$ to $8 \%$; instead the equivalent ones have a relatively lower increase from $3 \%$ to $7 \%$.

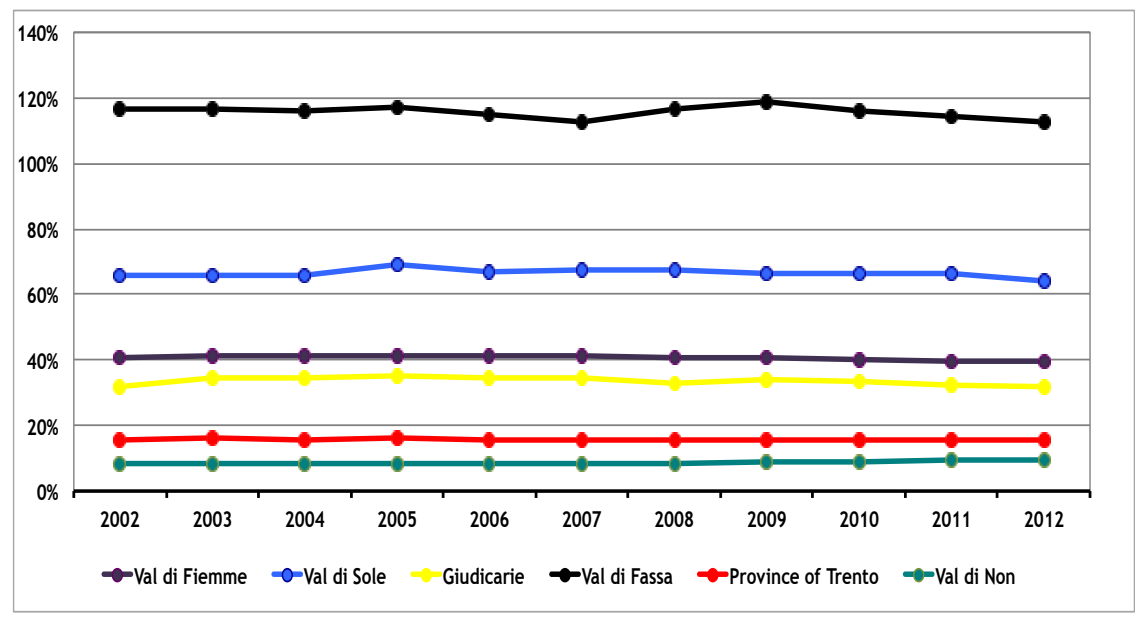

Figure 3: Dynamics of the ratio between equivalent and resident inhabitants.

The average "length of stay" of the tourists in the selected case-studies in the last decade is reported in Figure 4. It can be noticed that the differences are not high, only a $12 \%$ of fluctuation, showing that people come back in the same places to make their holidays but remain less. However the trend is towards a shorter period of holiday. 


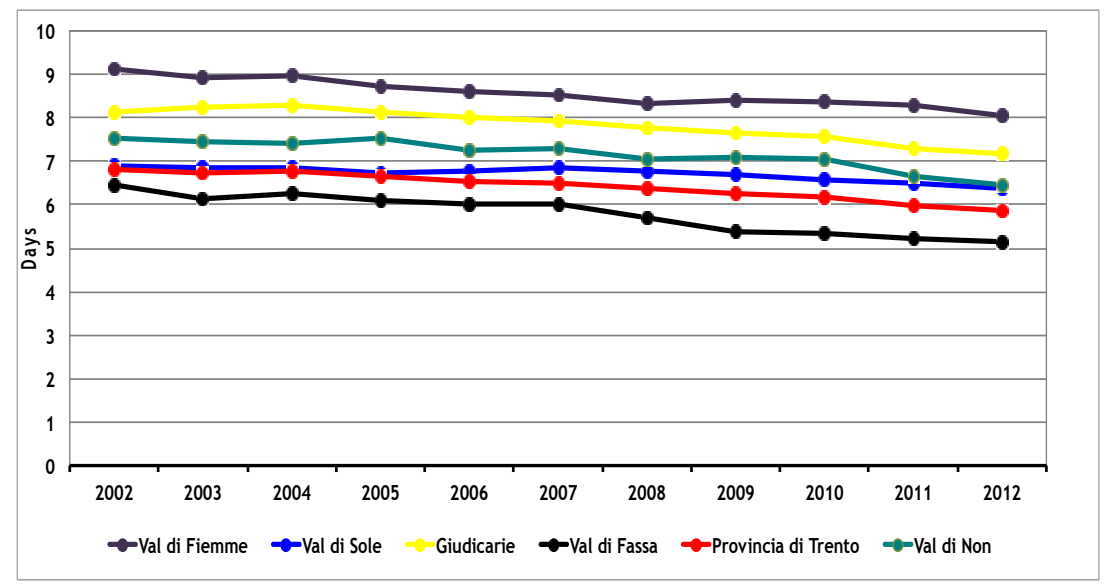

Figure 4: Length of tourist stay dynamics in the last decade in the chosen case-studies.

In Figure 5, on overview for the year 2012 is reported, concerning the arrivals and inhabitants in the selected case-studies. Data take into account the size of each municipality with respect to the case-study size and the impact of tourist arrivals in each municipality. The $\mathrm{X}$-axis represents the importance of the municipality towards the overall collection basin; the $\mathrm{Y}$-axis represents the impact of the tourist arrivals on the single municipality; the circle dimensions represent the overall tourist presences in a single municipality.

For the most tourist case $(112 \%$, Val di Fassa), similar dynamics are seen in all the 7 municipalities with two picks for Mazzin and Campitello; instead other scenarios have a lower dynamics with some peaks in the most tourist municipalities.

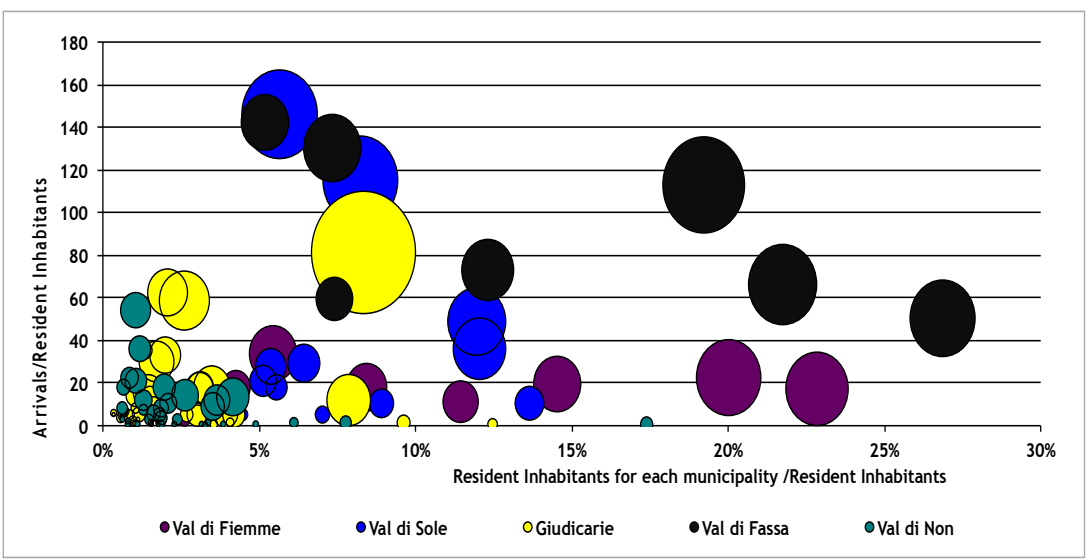

Figure 5: Tourist presence dynamics (circles show the overall presences in a locality). 
In order to understand the interaction of the tourist flux with the MSW production and their selective collection, in Figure 6 the percentage of SC as an average for the selected areas in the last 8 years is presented.

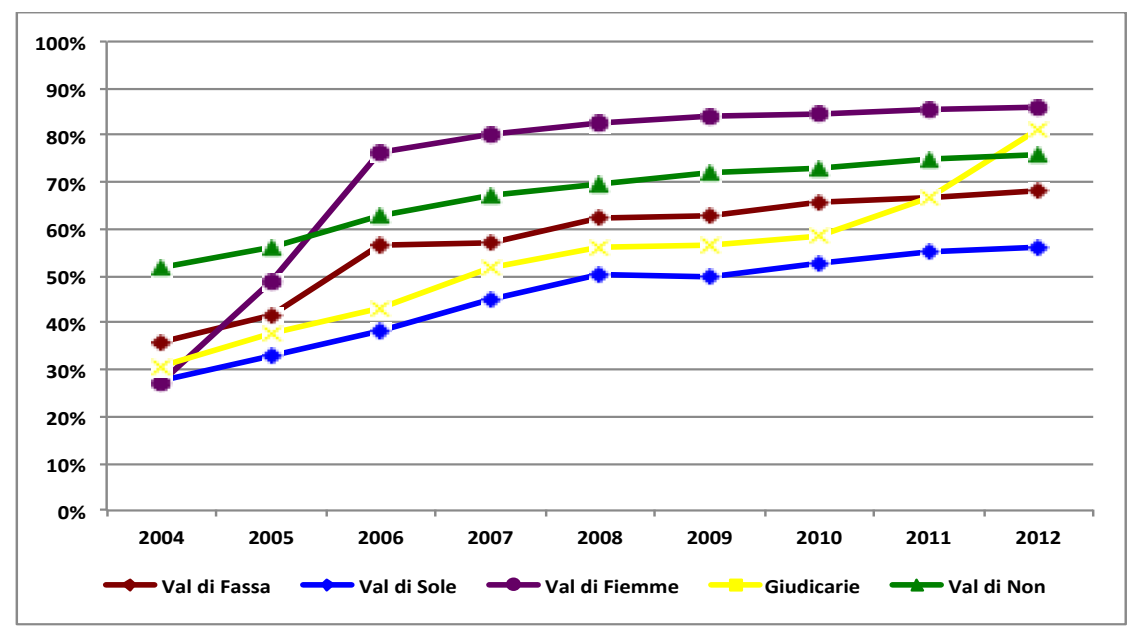

Figure 6: $\quad$ SC dynamics in the selected case-studies.

More in detail, in Table 2, the percentage of selectively collected waste in the year 2012 is reported month by month, for the Val di Fassa case. The most tourist months are both in winter and in summer and their effect is seen in the increase of the factions connected with the tourists meals and also the increase of RMSW and in the decrease of the ones connected only to the residential population (green and bulky waste or other factions).

Table 2: Percentage of SC in 2012 in the Val di Fassa case study (112\%).

\begin{tabular}{|c|c|c|c|c|c|c|c|c|c|c|c|c|}
\hline & \multicolumn{10}{|c|}{ Month $\left(\mathrm{kg}_{\text {fraction }} / \mathrm{kg}_{\text {total fraction }}\right)$} \\
\hline Fractions & 1 & 2 & 3 & 4 & 5 & 6 & 7 & 8 & 9 & 10 & 11 & 12 \\
\hline $\begin{array}{c}\text { food } \\
\text { waste }\end{array}$ & $15.9 \%$ & $12.9 \%$ & $11.6 \%$ & $4.1 \%$ & $3.0 \%$ & $4.3 \%$ & $12.2 \%$ & $17.1 \%$ & $7.0 \%$ & $3.5 \%$ & $2.2 \%$ & $6.2 \%$ \\
\hline $\begin{array}{c}\text { green } \\
\text { waste }\end{array}$ & $0.2 \%$ & $2.2 \%$ & $8.6 \%$ & $3.3 \%$ & $10.1 \%$ & $13.6 \%$ & $6.9 \%$ & $7.5 \%$ & $7.7 \%$ & $24.7 \%$ & $11.1 \%$ & $4.1 \%$ \\
\hline $\begin{array}{c}\text { paper and } \\
\text { cardboard }\end{array}$ & $9.5 \%$ & $9.0 \%$ & $9.4 \%$ & $6.3 \%$ & $5.7 \%$ & $6.6 \%$ & $11.3 \%$ & $13.8 \%$ & $7.3 \%$ & $5.6 \%$ & $5.6 \%$ & $9.9 \%$ \\
\hline $\begin{array}{c}\text { glass, } \\
\text { plastis } \\
\text { and cans }\end{array}$ & $11.7 \%$ & $10.6 \%$ & $10.2 \%$ & $7.3 \%$ & $8.5 \%$ & $5.5 \%$ & $9.6 \%$ & $13.2 \%$ & $7.5 \%$ & $7.2 \%$ & $3.9 \%$ & $4.8 \%$ \\
\hline $\begin{array}{c}\text { other } \\
\text { factions }\end{array}$ & $3.5 \%$ & $3.2 \%$ & $6.8 \%$ & $9.7 \%$ & $17.7 \%$ & $9.2 \%$ & $8.6 \%$ & $7.4 \%$ & $8.2 \%$ & $11.5 \%$ & $10.3 \%$ & $3.8 \%$ \\
\hline RMSW & $13.7 \%$ & $10.2 \%$ & $11.0 \%$ & $6.3 \%$ & $3.8 \%$ & $5.3 \%$ & $10.7 \%$ & $16.8 \%$ & $6.8 \%$ & $4.3 \%$ & $4.0 \%$ & $7.1 \%$ \\
\hline $\begin{array}{c}\text { bulky } \\
\text { waste }\end{array}$ & $2.7 \%$ & $3.8 \%$ & $6.2 \%$ & $8.3 \%$ & $14.3 \%$ & $9.2 \%$ & $8.9 \%$ & $8.7 \%$ & $7.1 \%$ & $11.5 \%$ & $11.4 \%$ & $7.8 \%$ \\
\hline
\end{tabular}


It is important to notice that, in the Val di Fassa, even if the population is more than double on yearly basis (112\% of population increase), food waste increases 3-4 times, meanwhile the other fractions connected to tourists are almost double. Also the RMSW doubles is quantity.

For the Val di Sole and Val di Fiemme cases $(65 \%$ and $39 \%$ of population increase), even if the surface is higher than in the above mentioned case, and the number of municipalities is almost double, the waste connected to tourists had an increase of $20 \%-30 \%$ and $25 \%-50 \%$ for the RMSW.

In the Giudicarie case (31\% of population increase), having the area a very high surface and high number of municipalities, but not all tourist, the waste connected to tourists had an increase of only $20 \%$, and $30 \%$ for RMSW.

The Val di Non case (only 10\% increase) confirms that tourists have influence on the waste production. In this case the increase is very low: $6 \%$ for the food waste and only $1 \%-2 \%$ for the other factions connected to tourism.

In Figure 7 the dynamics of the selective collection in 2012 for the five selected case-studies is reported month by month. The values are very high even if in three of the selected case-studies a landfill is present (case 2, 3, 5):

$>$ Case 1 (Val di Fassa): 68\% SC; since 2005: kerbside and underground street bins for RMSW; street bins for paper and cardboard, glass and cans, plastics; all integrated with $5 \mathrm{CRM}$ and $2 \mathrm{CRZ}$.

$>$ Case 2 (Val di Sole): 56\% SC; since 2001: street bins for all the fractions, that is food waste, paper and cardboard, plastics and cans and glass; all integrated with $10 \mathrm{CRM}$ and one under construction;

$>$ Case 3 (Val di Fiemme): 85\% SC; since 2004: kerbside collection for food waste and RMSW; street bins for paper and cardboard and glass and packaging; all integrated with $5 \mathrm{CRM}$ and $1 \mathrm{CRZ}$.

$>$ Case 4 (Giudicarie): 81\% SC; since 2001: street bins for RMSW, food waste, paper and cardboard, packaging, and glass; since 2011: underground locked street bins for RMSW; all integrated with 20 CRM and 2 CRZ.

> Case 5 (Val di Non): 76\% SC; since 2002: kerbside collection for food waste and RMSW; street bins for paper and cardboard and packaging and glass; all integrated with $21 \mathrm{CRM}$ and $2 \mathrm{CRZ}$.

However in the selected province in 1997 CRZ for different waste fractions were already implemented: 3 in the first case and in the second case, 2 in the third case and 7 and 6 in the last two cases. The SC changed strongly in the 2000s with the introduction of kerbside collection in some municipalities and also thanks to the introduction of the "Tariff - pay what you produce".

Analysing the data from Figure 7 it can be seen the influence on waste production of the tourists, by its increase in the summer and the winter months.

An important aspect to be noticed is that in the selected five cases, thanks to the SC efficiency, there is no need for a local plant for specific waste processing. Waste management is also supported by domestic composting of food and green waste.

The SC streams (tourism included) are sent to a centralised sorting plant for light packaging and to one anaerobic digester for biodegradable materials. The 
other selected streams are processed in and out the province depending on the receiving plants (glass, metals, paper and cardboard).

Today the produced RMSW is landfilled. The future scenario takes into account the bio-drying treatment (also for waste extracted from a landfill where baled were stored) and the Solid Recovered Fuel (SRF) production [20-22].

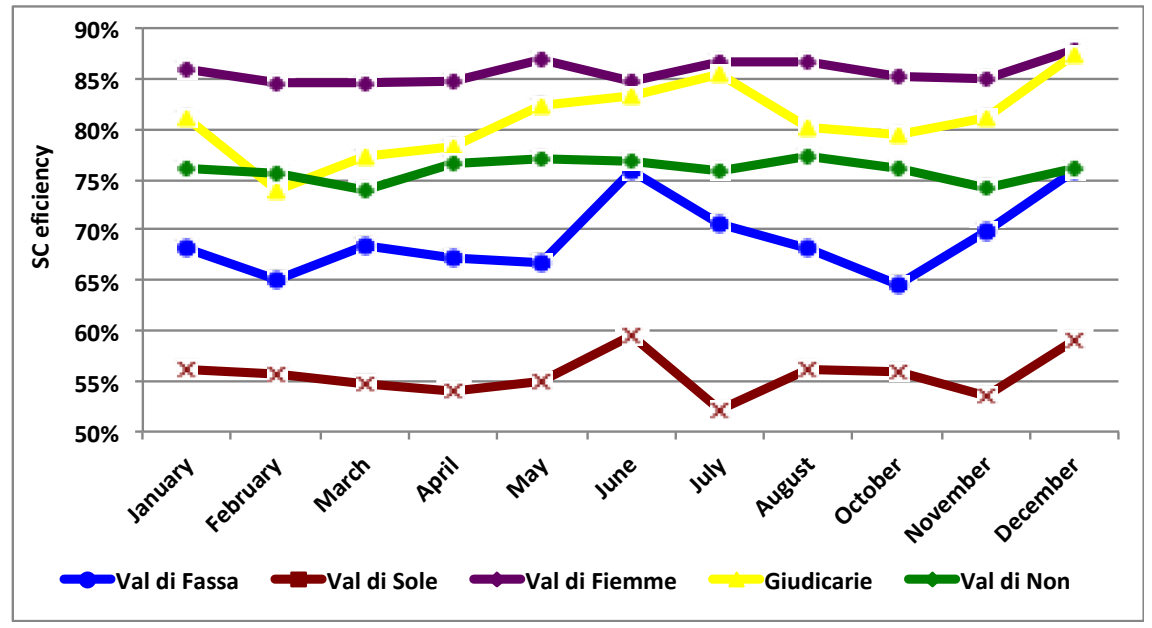

Figure 7: $\quad$ SC dynamics during the year 2012.

\section{Conclusions and outlooks}

The results of SC obtained in the studied province, come from years of MSW management planning characterized by:

$>$ A significant presence of decentralised small landfills; results demonstrate that this aspect didn't affect neither the evolution of SC nor the behaviour of tourists;

$>$ A significant availability of CRZ and CRM that supported the optimization of SC; possibly only a part of tourists take advantage of that, as these sites are often reached by car; the overall results demonstrate that there is no criticality about that;

$>$ A delayed decision about thermal treatments: an incineration plant was firstly proposed in 1997 but today this solution is going to be cancelled because of the reduced amount of RMSW to be managed locally; the behaviour of tourists contributed to this reduction;

$>$ A progressive interest towards mechanical biological treatments with SRF production that could be the future solution for the RMSW management in the selected province; taking into account the trend of the last years, the results of SC reached also in tourist areas seem to be stable enough to 
guarantee a steady amount of RMSW for the input of the future processing plant;

$>$ Concerning the single tourist, the trend of reducing the lasting of his/her stay could decrease the time available to learn correctly the SC rules; in reality the analysed province is characterised by a tourist that plans to come back every year;

$>$ The significant peaks of tourist presences in the analysed case studies seem to be easily managed at provincial level thanks to effect of dilution on wide scale.

\section{References}

[1] Dong, J., Chi, Y., Zou, D., Fu, C., Huang, Q., Ni, M., Energyenvironment-economy assessment of waste management systems from a life cycle perspective: Model development and case study. Applied Energy 114, pp. 400-408, 2014.

[2] Santibañez-Aguilar, J.E., Ponce-Ortega, J.M., Betzabe González- Campos, J., Serna-González, M., El-Halwagi, M.M., Optimal planning for the sustainable utilization of municipal solid waste. Waste Management 33(12), pp. 2607-2622, 2013.

[3] Ionescu, G., Rada, E.C., Ragazzi, M., Marculescu, C., Badea, A., Apostol, T., Integrated municipal solid waste scenario model using advanced pretreatment and waste to energy processes. Energy Conversion and Management 76, pp. 1083-1092, 2013.

[4] Rada, E.C., Istrate, I.A., Panaitescu, V., Ragazzi, M., Cirlioru, T.M., Apostol, T., A comparison between different scenarios of Romanian municipal solid waste treatment before landfilling, Environmental Engineering and Management Journal 9(4), pp. 589-596, 2010.

[5] Maeda, H. \& Hirose, Y., Expectation of empowerment as a determinant of citizen participation in waste management planning. Japanese Psychological Research 51(1), pp. 24-34, 2009.

[6] De Feo, G. \& De Gisi, S., Domestic separation and collection of municipal solid waste: Opinion and awareness of citizens and workers. Sustainability 2(5), pp. 1297-1326, 2010.

[7] Fragnelli, V., How to divide the costs of urban solid wastes collection among citizens? Economics and Policy of Energy and the Environment 3, pp. 51-64, 2012.

[8] Castagna, A., Casagrande, M., Zeni, A., Girelli, E., Rada, E.C., Ragazzi, M., Apostol T., 3R' from citizen point of view and their proposal: a casestudy, U.P.B. Scientific Bulletin, series D, Mechanical Engineering, 75(4), pp. 253-264, 2013.

[9] Zhang, J., Zhang, H., Zhang, J., Liu, F., Review of studies on environmental impacts of tourism waste. Proc. of the 2nd International Conference on Artificial Intelligence, Management Science and Electronic Commerce, pp. 6369-6372, 2011. 
[10] Mendes, P., Santos, A.C., Nunes, L.M., Teixeira, M.R., Evaluating municipal solid waste management performance in regions with strong seasonal variability, Ecological Indicators 30, pp. 170-177, 2013.

[11] Mihai, F.C., Tourism implications on local waste management. Case study: Neamț county, Romania, Present Environment and Sustainable Development 7(1), pp. 214-221, 2013.

[12] Shamshiry, E., Nadi, B., Bin Mokhtar, M., Komoo, I., Saadiah Hashim, H., Yahaya, N., Integrated models for solid waste management in tourism regions: Langkawi Island, Malaysia. Journal of Environmental and Public Health, art. no. 709549, 2011.

[13] Mateu-Sbert, J., Ricci-Cabello, I., Villalonga-Olives, E., Cabeza-Irigoyen, E., The impact of tourism on municipal solid waste generation: The case of Menorca Island (Spain). Waste Management 33(12), pp. 2589-2593, 2013.

[14] http://www.consiglio.provincia.tn.it/documenti_pdf/clex_12636.pdf

[15] http://www.adep.provincia.tn.it

[16] Rada, E.C. \& Ragazzi M., Selective collection as a pretreatment for indirect solid recovered fuel generation, Waste Management 34(2), 291-297, 2014.

[17] Rada, E.C., Ragazzi, M., Fedrizzi, P., WEB-GIS oriented system viability for municipal solid waste collection optimization in developed and transient economies, Waste Management 33(4), 785-792, 2013.

[18] Rada, E.C., Effects of MSW selective collection on waste-to-energy strategies, WIT Transactions on Ecology and the Environment 176, pp. 215-223, 2013.

[19] Ragazzi, M. \& Rada, E.C., Effects of recent strategies of selective collection on the design of municipal solid waste treatment plants in Italy, WIT Transactions on Ecology and the Environment 109, pp. 613-620, 2008.

[20] Rada, E.C. \& Andreottola, G., RDF/SRF: which perspectives for its future in the EU, Waste Management, 32/6, pp. 1059-1060, 2012.

[21] Rada, E.C., Ragazzi, M., Badea, A., MSW bio-drying: design criteria from 10 years of research, UPB Scientifc Bulletin, series D, 74/3, pp. 209-216, 2012.

[22] Velis, C.A., Cooper, J., Are solid recovered fuels resource-efficient? Waste Management and Research, 31(2), pp. 113-114, 2013. 